\title{
The use of biologics for immune modulation in allergic disease
}

\author{
Willem van de Veen ${ }^{1,2}$ and Mübeccel Akdis \\ 'Swiss Institute of Allergy and Asthma Research (SIAF), University of Zurich, Davos, Switzerland. ${ }^{2}$ Christine Kühne - Center for Allergy Research and Education (CK-CARE), Davos, Switzerland.
}

\begin{abstract}
The rising prevalence of allergies represents an increasing socioeconomic burden. A detailed understanding of the immunological mechanisms that underlie the development of allergic disease, as well as the processes that drive immune tolerance to allergens, will be instrumental in designing therapeutic strategies to treat and prevent allergic disease. Improved characterization of individual patients through the use of specific biomarkers and improved definitions of disease endotypes are paving the way for the use of targeted therapeutic approaches for personalized treatment. Allergen-specific immunotherapy and biologic therapies that target key molecules driving the Th2 response are already used in the clinic, and a wave of novel drug candidates are under development. In-depth analysis of the cells and tissues of patients treated with such targeted interventions provides a wealth of information on the mechanisms that drive allergies and tolerance to allergens. Here, we aim to deliver an overview of the current state of specific inhibitors used in the treatment of allergy, with a particular focus on asthma and atopic dermatitis, and provide insights into the roles of these molecules in immunological mechanisms of allergic disease.
\end{abstract}

\section{Immunological mechanisms of allergy} and tolerance

Allergic sensitization and type I and IV hypersensitivity reactions. Allergies develop as a result of an immune response to distinct environmental protein antigens, called allergens. In recent years, substantial progress has been made in elucidating mechanisms that drive the initiation and persistence of allergic reactions. Development of allergic diseases starts with a sensitization phase (Figure 1). Key processes driving allergic sensitization include activation and maturation of dendritic cells (DCs) upon contact with allergens, epithelial alarmins, and infectious agents, followed by clonal expansion of allergen-specific Th2 cells that are polarized toward producing type 2 cytokines, including IL-4, IL-5, IL-9, IL-13, IL-25, IL-31, IL-33, and thymic stromal lymphopoietin (TSLP) (1). Th2 cells induce class switch recombination of B cells to the IgE isotype and differentiation to IgE-producing plasma cells. IgE can bind to the high-affinity IgE receptor FceRI on basophils and mast cells. Moreover, IgE can also enhance allergen uptake and presentation through so-called facilitated antigen presentation $(2,3)$. These processes form the basis of allergic sensitization.

Subsequent exposure to the culprit allergen can trigger IgEmediated FceRI cross-linking on mast cells and basophils, leading to a type I hypersensitivity reaction. During the early phase of this reaction, which starts within minutes after allergen exposure, mast cells and/or basophils degranulate and release a range of preformed and newly synthesized mediators including histamine, leukotrienes, heparin, and several proteases, as well as

Conflict of interest: The authors have declared that no conflict of interest exists. Copyright: @ 2019 American Society for Clinical Investigation Reference information: / Clin Invest. 2019;129(4):1452-1462. https://doi.org/10.1172/JCI124607. cytokines and growth factors such as TNF- $\alpha$ and VEGFA (4). After 2 to 6 hours of exposure, the late phase of the reaction manifests, characterized by edema, erythema in skin, and airway narrowing and mucus secretion in the airways. These symptoms are caused by the recruitment and activation of Th2 cells, eosinophils, basophils, and tissue-resident mast cells. Persistent allergen exposure can produce a chronic phase of inflammation that represents a distinct Th2 type of type IV hypersensitivity (5). Classical type IV hypersensitivity denotes tuberculin-type hypersensitivity with the involvement of Th1 cells. In allergic inflammation a cellular late-phase response develops, characterized by tissue inflammation with eosinophils, Th2 cells, and type 2 innate lymphoid cells (ILC2s); remodeling of vasculature and smooth muscle cells; and extracellular matrix formation and fibrosis $(4,5)$. In the clinical setting, this chronic inflammation prevails and forms the basis for the main tissue inflammation mechanisms referred to as Th2 or type 2 inflammation in asthma, atopic dermatitis (AD), chronic rhinosinusitis (CRS) with nasal polyps, and allergic rhinitis. Notably, approximately $20 \%$ of pediatric and adult AD patients and $10 \%$ to $20 \%$ of pediatric and $50 \%$ of adult asthma patients show a nonallergic and non-eosinophilic phenotype. Most of the CRS without nasal polyps patients also fall into this non-type 2 category. So far, these non-type 2 diseases have not been efficiently targeted with biologics, and their pathogenetic mechanisms are associated with a broad range of environmental and/or host factors, such as smoking, exposure to pollutants, work-related agents, chronic infections, and obesity (6).

Mechanisms of immune tolerance to allergens. In recent years, substantial efforts have been made to improve the classification of patients suffering from allergic disease in order to facilitate the development of personalized medicine. A key concept in this regard comes from the determination of so-called disease 


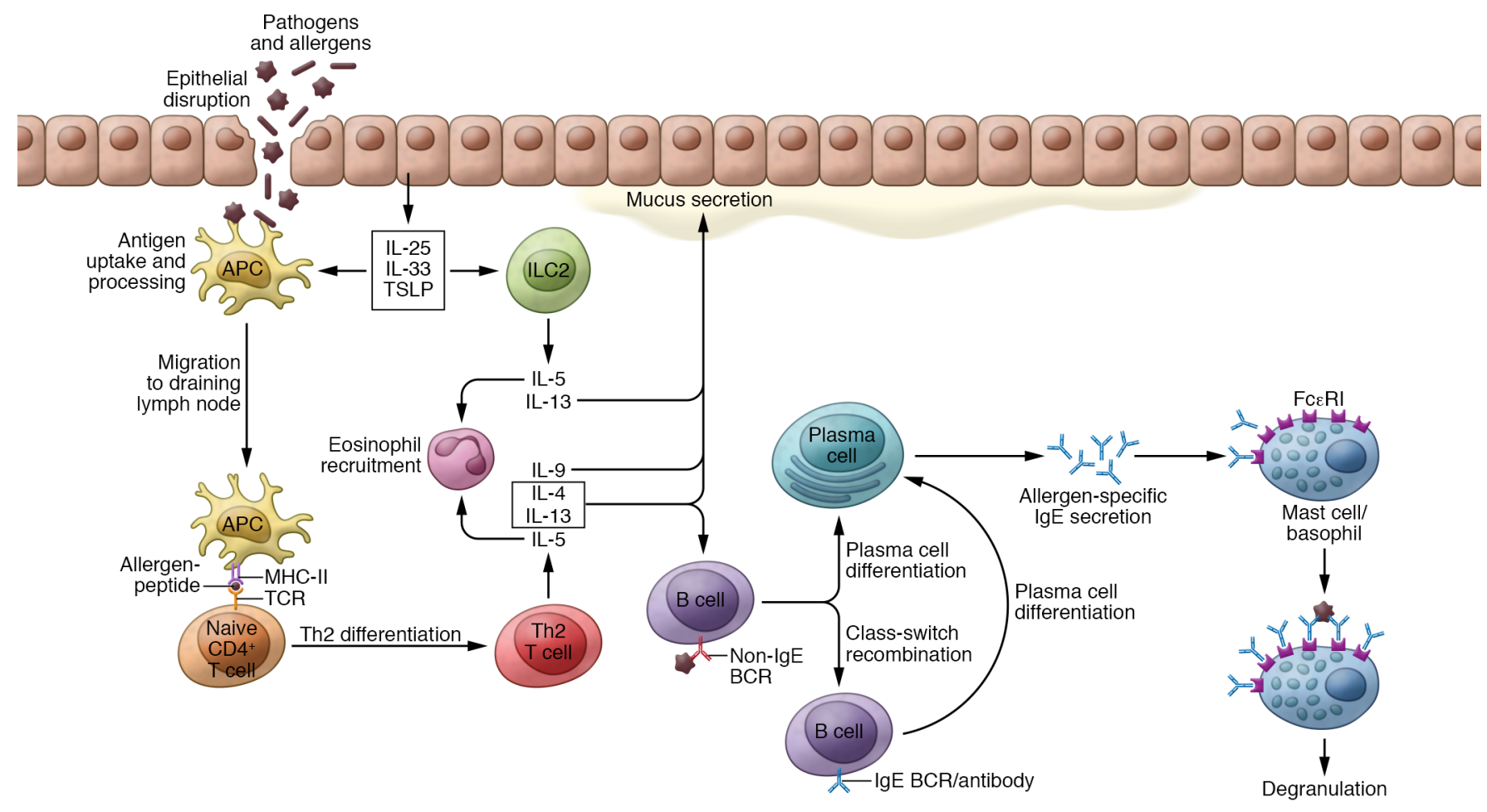

Figure 1. Key cellular and molecular players in allergic sensitization. Allergens and pathogens that have passed the skin or mucosal epithelium are phagocytosed by antigen-presenting cells (APCs). These APCs mature as a result of cytokines produced by epithelial cells, then migrate to draining lymph nodes, where they present allergen-derived peptides to CD4+ $T$ cells and induce differentiation to Th2 cells. ILC2s are also activated by epithelial cellderived cytokines such as IL-25, IL-33, and TSLP. Th2 cells and ILC2s produce type 2 cytokines such as IL-4, IL-13, IL-5, and IL-9. IL-4 and IL-13 drive IgE class switch recombination of B cells, leading to allergen-specific IgE production. Allergen-specific IgE binds to FcERI on mast cells and basophils. IL-4, IL-9, and IL-13 promote mucus secretion by goblet cells, whereas IL-5 is instrumental in eosinophil recruitment. TCR, T cell receptor.

endotypes, which describe a subtype of a disease condition defined by distinct pathophysiological mechanisms, in contrast to disease phenotypes, which define disease characteristics without implying a mechanism. Identification of biomarkers that accurately and objectively examine pathogenic processes and responses to therapeutic interventions is critical for the development of individual therapies. The term "theratype" has been coined to describe subsets of patients that respond well to a certain therapeutic intervention (7-12).

The induction of immune tolerance involves molecular mechanisms of anergy, deletion, suppression, immune privilege, and ignorance. This Review mainly focuses on immunological mechanisms of peripheral tolerance to allergens. Various models have been used to study the mechanisms that drive immune tolerance to allergens. These include the in-depth analysis of immunological parameters in allergic patients treated with allergen-specific immunotherapy (AIT) and in healthy individuals who are chronically exposed to high-doses of allergens, such as cat owners and nonallergic beekeepers $(13,14)$. Early desensitization of mast cells and basophils (15), induction of regulatory $\mathrm{T}(13,16-18)$ and $\mathrm{B}$ cells (19-22), anergy in Th2 cells, and probably apoptosis of highly activated Th2 cells (23), suppression of eosinophil activation and migration (24), and production of allergen-specific IgG4 antibodies $(25,26)$ are key processes in the development of immune tolerance in response to AIT (27). In humans most of these findings are correlative, but a recent study reported that anti-Fel d 1-IgG4 mAb injection induced the cat allergen-blocking antibody effect within a week to the same extent as did AIT (28). Knowledge obtained from these studies paved the way for the development of diagnostic tools and innovative drugs, particularly biologics that specifically target select mediators of allergic immune responses (7, 27, 29, 30). To date there is no direct evidence that any of the biologics discussed in this Review induce allergen tolerance; however, their usage together with immune tolerance-inducing AIT is open for further studies.

\section{Targeting the mediators of the allergic response}

Improved understanding of the immunological mechanisms that regulate allergy development and allergen tolerance allows a systematic strategy for drug design aimed at targeting specific molecules with a known or suspected role in these processes. The feedback from preclinical work and clinical trial results provide an invaluable data resource to further elucidate these mechanisms. Here, we describe the major strategies aimed at prevention and treatment of allergic disease and discuss the insights they provide into the immunological mechanisms of allergy and tolerance.

Recent advances in the field of therapeutic antibodies have led to the development of a wide range of biologic drug candidates (mostly mAbs) for the treatment of allergic diseases (listed in Table 1). These can be broadly grouped into two distinct groups: (a) biologics targeting cytokines and cytokine receptors, and (b) biologics targeting soluble and membrane-bound IgE. 


\section{Table 1. Biologic drug candidates for the treatment of allergic diseases}

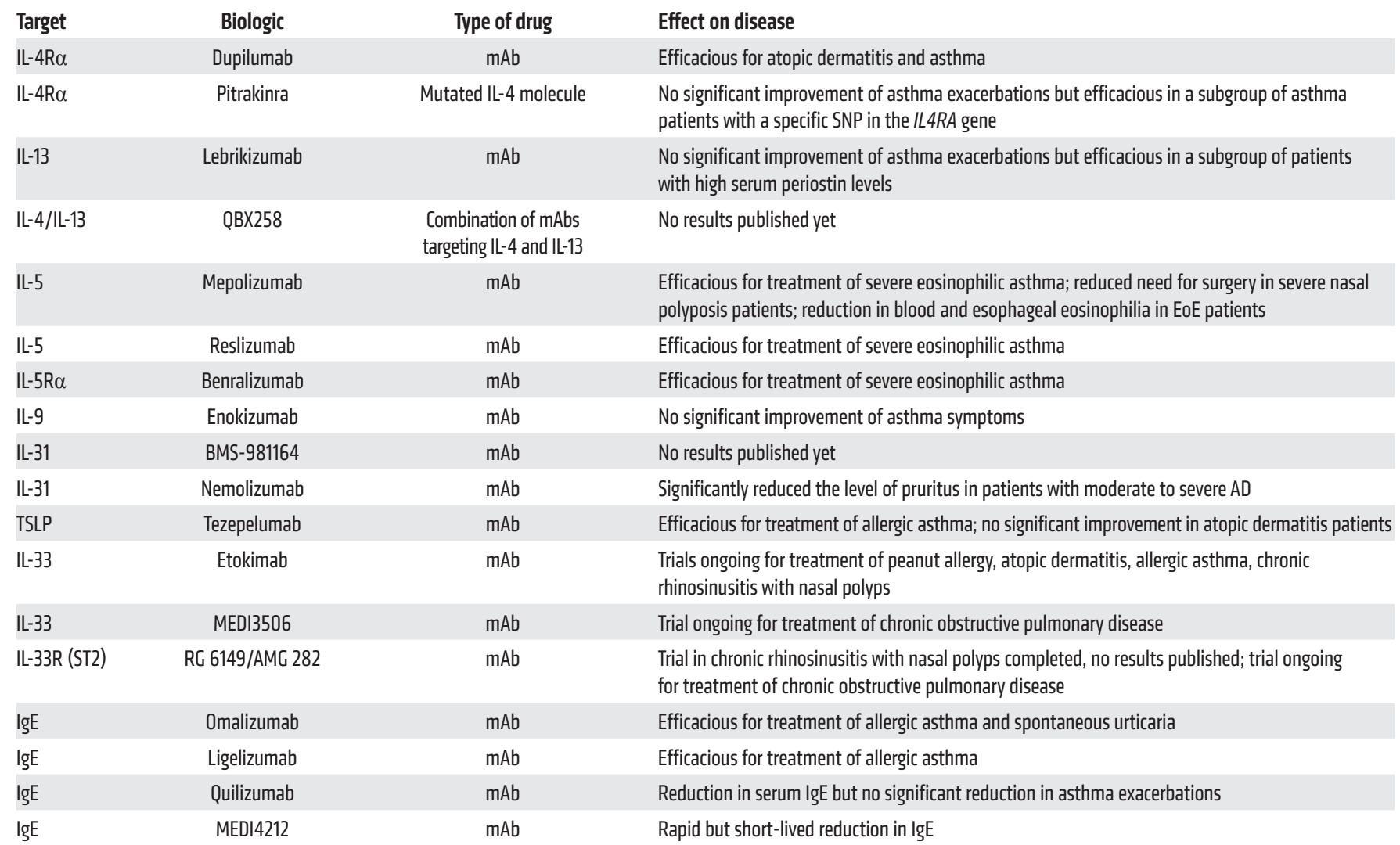

\section{Targeting classical Th2 effectors using IL-4/IL-13 interference}

IL-4 and IL-13 are structurally and functionally related cytokines that display approximately $25 \%$ sequence homology. Both are composed of four $\alpha$-helix bundles. These cytokines are pivotal for both IgE sensitization and late-phase allergic responses. IL-4 and IL-13 share many functional characteristics, including their capacity to induce IgE class switch recombination (albeit only in humans, as IL-13 cannot induce IgE in mice), airway hyperreactivity, mucus production, goblet cell hyperplasia, smooth muscle cell contraction, and airway remodeling $(1,31)$.

Both IL-4 and IL-13 are produced by Th2 cells, basophils, mast cells, and NKT cells. ILC2s can also produce small amounts of IL-4, but their capacity to produce IL-13 is much higher $(1,32)$. IL-4 signals through receptors consisting of heterodimers of the IL- $4 \mathrm{R} \alpha$ and the common Y chain and through receptors comprising a heterodimer of IL-4R $\alpha$ chain and IL-13R $\alpha 1$ or IL-13R $\alpha 2$, a signaling pathway it shares with IL-13 (Figure 2 and ref. 1). The fact that IL-4 and IL-13 share a receptor explains their large functional overlap. Several drugs targeting IL-4, IL-13, and their common receptor have been developed. However, so far only dupilumab, an $\mathrm{mAb}$ targeting IL- $4 \mathrm{R} \alpha$, has proven efficacious, and it has been licensed for the treatment of AD (33) and asthma (34-37). These findings suggest that inhibiting both IL- 4 and IL-13 is necessary for clinically successful results, but it should be noted here that unsuccessful studies cannot rule out any relevant molecular mechanisms, because these drugs depend on many pharmacodynamic factors, such as dose, affinity, half-life, etc. A clinical study in 2000 showed that a single dose of anti-IL- $5 \mathrm{mAb}$ decreased blood eosinophils for up to 16 weeks and sputum eosinophils at 4 weeks, which has considerable therapeutic potential for asthma and allergy. However, the data did not support the treatment effect of anti-IL- $5 \mathrm{mAb}$ for late asthmatic response and airway hyperresponsiveness (38).

Dupilumab's use for other applications is currently being explored. Promising results have been obtained for patients with chronic sinusitis and nasal polyposis $(39,40)$. A recent case report described the successful treatment of a recalcitrant bullous pemphigoid patient with dupilumab (41). Several other biologics have been developed to target IL-4R $\alpha(42,43)$. Among these is pitrakinra (trade name Aerovant), a biologic drug that, in contrast to other biologics targeting the IL-4/IL-13 pathway, is not an mAb. Pitrakinra is a recombinant IL-4 that contains two targeted point mutations and functions as an antagonist of $\mathrm{IL}-4 \mathrm{R} \alpha(44,45)$. Thus, its expected mode of action is analogous to that of dupilumab. Inhalation treatment of asthma patients with pitrakinra did not show an overall significant improvement of asthma exacerbations (45). Interestingly, a subgroup analysis revealed that patients with a specific SNP (rs8832GG) in the 3 '-untranslated region of the $I L 4 R A$ gene did significantly improve exacerbations 
A

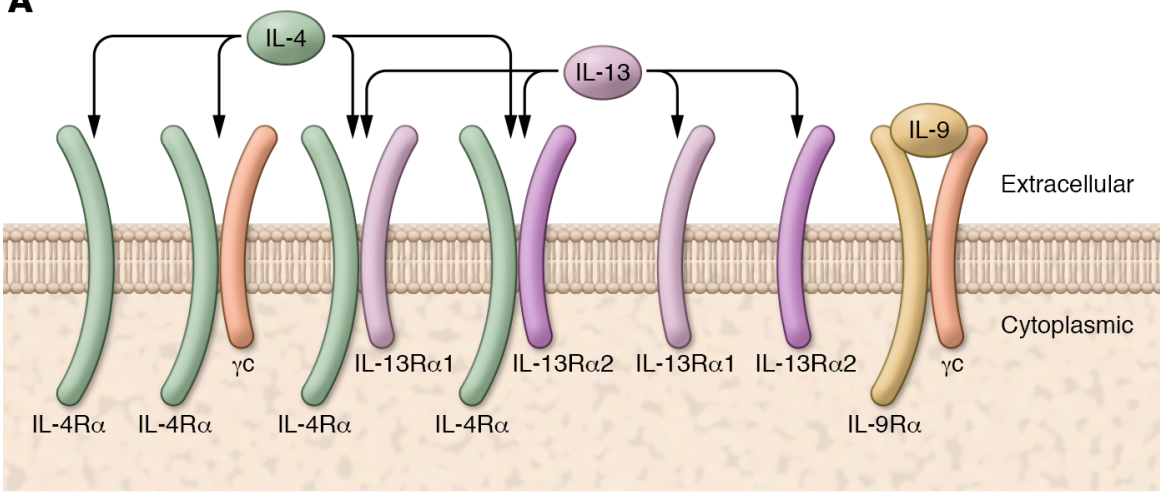

B
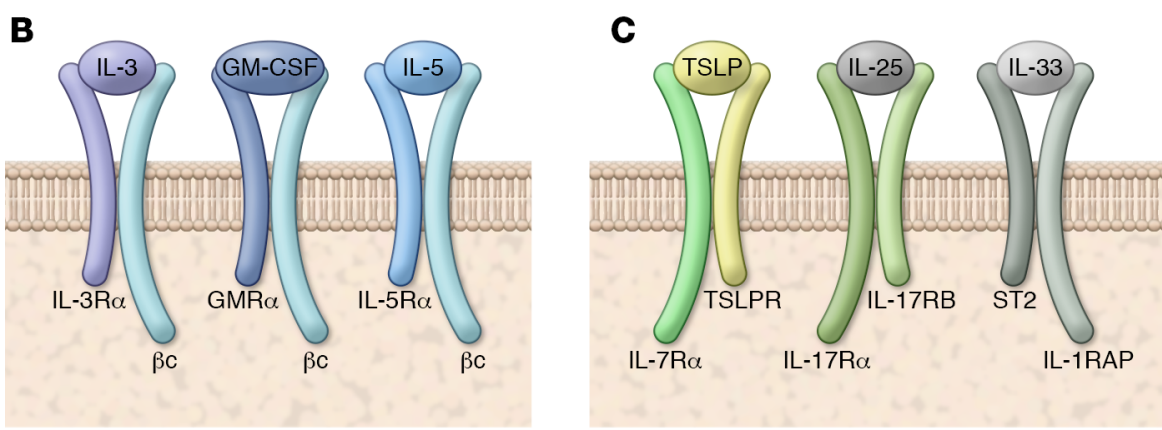

D

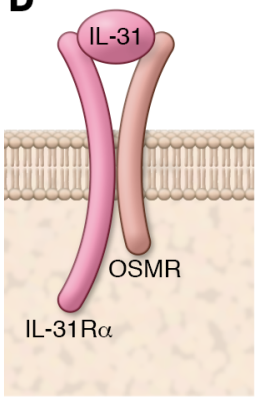

Figure 2. Receptors of key cytokines involved in Th2 responses. (A) IL-4 and IL-13 partially share their receptor complexes. One of the IL-4 receptor complexes and the IL-9 receptor both use the common $\gamma$ chain $(\gamma c)$ for signaling. $\gamma c$ is also involved in IL-2, IL-7, IL-15, and IL-21 signaling (not shown). (B) IL-5 signals through a heterodimer consisting of IL-5R $\alpha$ and the common $\beta$ chain $(\beta c)$, which is also involved in IL-3 and CM-CSF signaling. (C) The receptors for TSLP, IL-25, and IL-33 do not share any subunits. (D) The IL-31 receptor is composed of IL-31 receptor $\alpha$ (IL-31RA) and oncostatin M receptor $\beta$ (OSMR).

IL-4 (dectrekumab, also known as VAK 694) and anti-IL-13 (QAX576, listed under the name QBX258) agents. This approach has the potential to tackle the redundancy problem, but results have not yet been published.

\section{Interfering with eosinophil responses by targeting IL-5}

IL-5 is produced by Th2 cells, mast cells, NKT cells, activated eosinophils, and ILC2s (50-53). It binds to IL-5R, a heterodimeric receptor composed of an IL-5R $\alpha$ subunit responsible for binding IL-5 and the common $\beta$ chain responsible for signaling. IL-5R is expressed on eosinophils, basophils, mast cells, and B cells (Figure 2). The common $\beta$ chain is also responsible for IL-3 and GM-CSF signaling (1). Eosinophils inflict tissue damage by degranulating and secreting a range of mediators including histamine, arylsulfatase, eosinophil peroxidase, and others (54). Because of its potent induction of eosinophil activation, survival, and proliferation, IL-5 contributes substantially to the development of allergic airway inflammation in asthma $(1,55)$. This also makes it an attractive target for therapeutic intervention.

Several biologics directly target IL-5 itself (mepolizumab and reslizumab) or IL-5R $\alpha$ (benralizumab) (55). All three drugs were found to reduce the rate of asthma exacerbations in patients with severe eosinophilic asthma by approximately half and are now approved for the treatment of eosinophilic asthma (56-61). Long-term intravenous application of reslizumab produced sustained improvements in lung function and asthma exacerbations for up to 2 years in patients with moderate to severe eosinophilic asthma (62).

Identification of accurate predictive biomarkers to identify which patients will respond to therapy will help to further

(45). Therefore, this genetic variant could be considered a biomarker for patients with a high likelihood of responding to this treatment. Contemporaneous with this trial, a successful phase II trial with lebrikizumab (an anti-IL-13 $\mathrm{mAb}$ ) for treatment of asthma indicated the secreted protein periostin as a biomarker for patient selection (46); however, lebrikizumab did not show efficacy in a multicenter phase III trial (47).

Several biologics that directly target IL-4 or IL-13, rather than their receptors, have failed to meet their clinical endpoints in asth$\mathrm{ma}(43,48,49)$. The main reason for this most likely stems from the large degree of redundancy in biological function between IL-4 and IL-13. A recent study (NCT01479595; ClinicalTrials.gov) assessed the efficacy of treating asthma patients with a combination of anti- improve the success of treatment with such IL-5-targeting biologics. Patients with a count of $\geq 150$ eosinophils per microliter displayed the strongest reduction in asthma exacerbation upon treatment with mepolizumab (63). Anti-IL-5 or anti-IL-5R $\alpha$ therapy was also investigated in other patient groups that suffer from eosinophil-associated diseases. Patients with eosinophilic nasal polyposis who were treated with mepolizumab every 4 weeks for 25 weeks were less likely to require surgery as a treatment for their condition (64). Another condition that may benefit from anti-IL-5 therapy is eosinophilic esophagitis (EoE). Anti-IL-5 therapy led to marked decreases in peripheral blood and esophageal eosinophilia in EoE patients and improved clinical outcomes in both adults and children (65-67) in some studies, but 


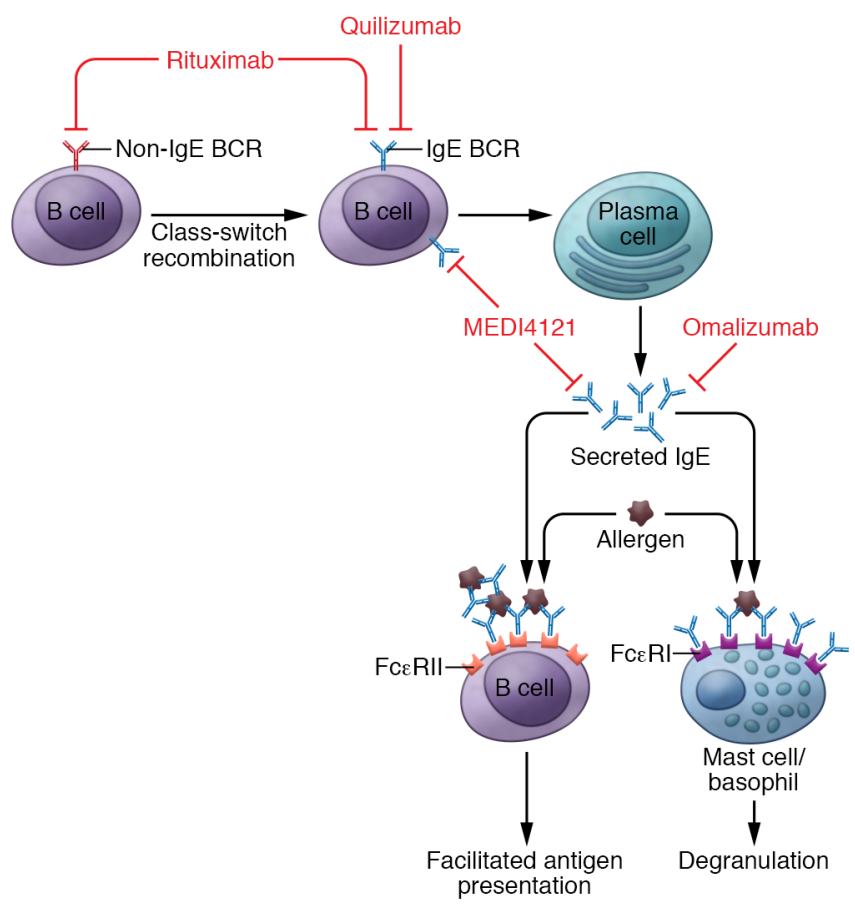

not recent ones (68). Identification of biologic-responsive EoE endotypes and investigation of biologics combined with other therapies may help elucidate a role for biologics in EoE (69).

\section{Interfering in IL-9-mediated Th2 and mast cell responses}

IL-9 is produced by Th2 cells, ILC2s, Th9 cells, and granulocytes (including basophils, eosinophils, and possibly neutrophils), as well as mast cells (70-76). It signals through the IL-9 receptor complex, comprising an IL-9R $\alpha$ chain and the common $\gamma$ chain $(\gamma c)$, which is expressed on B and T cells, epithelial cells, and mast cells (Figure 2 and ref. 1). IL-9 plays a role in allergic disease by promoting IgE production by B cells, chemokine production and mucus secretion by epithelial cells, and mast cell proliferation (77, 78). The anti-IL-9 mAb enokizumab (MEDI528) has been evaluated in moderate to severe asthma but failed to demonstrate an improvement in any of the trials (79). The impressive impact of IL-9 in mouse models was not replicated in human asthma. Further studies could possibly identify subgroups of patients with distinct asthma endotypes that may benefit from anti-IL-9 therapy. Anti-IL-9 could also be considered in the context of a combination therapy together with AIT: OVA-sensitized mice treated with an oral immunotherapy regimen and antiIL-9 showed significant reductions in allergic symptoms, OVAspecific IgE levels, and eosinophil counts, as well as reduced Th2 responses and increased FoxP3 and IL-10 expression (80).

\section{Fighting the itch response by targeting IL-31}

IL-31 is produced mainly by Th2 cells and to a lesser extent by $\mathrm{CD}^{+} \mathrm{T}$ cells. It signals through a heterodimeric receptor consisting of IL-31R $\alpha$ and oncostatin $M$ receptor $\beta$, which is expressed by keratinocytes, epithelial cells, eosinophils, basophils, monocytes, and dorsal root ganglia (Figure 2 and refs. 81,
Figure 3. Targeting IgE and IgE production. Total B cell depletion using the anti-CD2O antibody rituximab will target all B cells. Quilizumab targets the IgE BCR, leading to depletion of B cells and plasmablasts expressing IgE. Omalizumab targets free IgE, while the $B$ cells and plasma cells producing IgE are not affected. MEDI4121 targets both membrane IgE and free $\mathrm{IgE}$. The use of IgE-targeting biologics is aimed at reducing the amount of available allergen-specific IgE that facilitates mast cell and basophil degranulation and antigen presentation.

82). It has been shown to promote Th2-driven inflammation (83). The main property of IL-31 that gives it a unique role is its ability to induce pruritus in conditions such as $\mathrm{AD}(82)$. This is most likely related to the fact that the IL-31 receptor complex is expressed at high levels on dorsal root ganglia, where the cell bodies of cutaneous neurons are located.

Currently two mAbs that target IL-31 signaling are under development. BMS-981164 binds IL-31, while nemolizumab is directed against IL-31R $\alpha$ (82). A phase I trial of BMS-981164 in AD patients was completed in 2015 (NCT01614756), but no results have been published yet. A phase II trial demonstrated that subcutaneous monthly treatment with nemolizumab significantly reduced the level of pruritus after 3 months in patients with moderate to severe $\mathrm{AD}(84)$. A later study showed that this beneficial effect was maintained for up to 64 weeks (85). Interestingly, an experiment in which healthy controls and AD patients were challenged with topical IL-31 by skin prick testing showed no direct induction of itch at the provocation site in most individuals, while a late-onset itch response, with a delay of over 2 hours, was reported by 9 of 30 subjects. This suggests that IL-31 may exert its pruritic effects indirectly through keratinocyte activation rather than directly through interaction with cutaneous nerves (86).

\section{Targeting IL-25-, IL-33-, and TSLP-mediated epithelium-immune cell interactions}

Epithelial cells are instrumental in orchestrating allergic immune responses. They are an important source of the Th2-inducing cytokines IL-25, IL-33, and TSLP (87). Considerable efforts have been made to elucidate the distinct roles of IL-25, IL-33, and TSLP in both early and late phases of allergic responses. Exposure to allergens, infections, or tissue damage can promote the release of these cytokines from the epithelium. Early priming of the allergen-specific immune responses with these cytokines may play an important role in the development of Th2 priming by DCs and type 2 ILCs. Decreased production of these cytokines represents an important target for the priming of type 2 immune responses as discussed below. Currently, IL-33 and TSLP are promising targets, but IL-25-related studies are not ongoing on a large scale. This may be due to more exhaustive effects of IL-33 and TSLP in in vitro and in vivo studies compared with IL-25, although further studies are needed (88).

IL-25. IL-25 (also referred to as IL-17E) is produced by epithelial cells in the gut, lung, and sinus, as well as by Th2 cells, basophils, mast cells, and eosinophils $(1,89)$. Recent studies demonstrated that intestinal tuft cells constitutively produce IL-25 to sustain ILC2 homeostasis in the murine lamina propria (90). IL-25 binds to a heterodimeric receptor consisting of IL-17RA and IL-17RB (Figure 2). IL-25 induces secretion of IL-4, IL-5, and IL-13 from 
Th2 cells and induces IL-5 and IL-13 secretion from ILC2s (89). Therefore, IL-25 is a promising drug target for allergic disease. Several studies have demonstrated the potential of IL-25 neutralization in the context of allergic airway inflammation and CRS with nasal polyps, but human therapeutics targeting IL-25 are not yet in clinical development $(91,92)$.

Neutralization of IL-25 during the sensitization phase in a murine model of allergic airway inflammation significantly reduced IL-5 and IL-13 production, reduced eosinophil inflammation and IgE production, and prevented allergic airway hyperresponsiveness (AHR). When administered during the challenge phase, anti-IL-25 could also prevent AHR, indicating that IL-25 may also play a role during the effector phase of the allergic response (93).

TSLP. TSLP is a member of the IL-2 cytokine family that is produced by epithelial cells of the skin, gut, and lung $(94,95)$. Basophils, mast cells, and DCs have also been shown to produce TSLP (96-98). TSLP has two isoforms, of which the short isoform is constitutively expressed, while the long isoform is released in response to pathogen exposure, TLR engagement, and stimulation with cytokines such as IL-4, IL-13, IL-1 $\beta$, and TNF- $\alpha$. The heterodimeric receptor for TSLP, which is composed of the TSLP receptor (TSLPR) and IL-7R $\alpha$, is expressed by DCs, monocytes, B cells, mast cells, and ILC2s (Figure 2 and ref. 99). DCs and ILCs are considered prime target cells for TSLP in the context of allergic responses (100-102). TSLP-stimulated DCs upregulate OX4OL, CD80, and CD86 and induce Th2 differentiation from naive $\mathrm{CD}^{+} \mathrm{T}$ cells (103). Since TSLP acts on DCs that prime Th2 cells, blocking TSLP is expected to reduce the development or enhancement of Th2 responses. TSLP is upregulated in airways of asthma patients, and it was found that an SNP in the TSLP locus was associated with protection from asthma $(104,105)$.

The TSLP-targeting therapeutic antibody tezepelumab (AMG 157 ) is currently under investigation for the treatment of asthma and AD. A phase I trial in 31 patients with mild allergic asthma showed that three monthly doses of tezepelumab attenuated most measures of allergen-induced early and late asthmatic responses. This was associated with decreases in blood and sputum eosinophils and exhaled nitric oxide (106). In a phase II study of tezepelumab for the treatment of $\mathrm{AD}$, improvements over placebo were not statistically significant (107). A phase II trial with a duration of 1 year assessing the efficacy and safety of monthly treatment with tezepelumab in patients with uncontrolled asthma showed a significant reduction in asthma exacerbations as well as improved lung function. This clinical improvement was independent of eosinophil counts at baseline (108). Tezepelumab is also currently being tested in combination with AIT with the aim of enhancing the efficacy of immunotherapy in cat-allergic patients (NCT02237196). These results indicate that anti-TSLP therapy may be effective for the treatment of asthma.

IL-33. IL-33 is a member of the IL-1 cytokine family that is produced by epithelial cells (109). Its activity is significantly increased upon proteolytic cleavage by elastase or cathepsin G (1, 110). IL-33 signals through a heterodimeric receptor comprising ST2 and IL-1 receptor accessory protein (IL-1RAP), the latter of which is expressed on mast cells, macrophages, hematopoietic stem cells, eosinophils, ILC2s, a subset of Th2 cells, and NKT cells
(Figure 2 and refs. 1, 110). IL-33 plays a pivotal role in allergic sensitization through its induction of Th2 responses (111), and is an important player in DC responses to house dust mites (112). IL-33 and ST2 have been identified as susceptibility loci for asthma. A recently identified subset of Th2 cells, called Th2A cells, included all allergen-specific Th2 cells in a cohort of peanut-allergic individuals. These Th2A cells displayed upregulated ST2 expression and produced IL-4 and IL-5 upon IL-33 stimulation (113). Soluble ST2 functions as a decoy receptor that suppresses IL-33-mediated responses. Recent data showed that IL-33-mediated allergic sensitization in a murine model for gastrointestinal allergy occurred independently of TSLP, while TSLP-driven allergic disease could not be induced in mice deficient in the IL-33 receptor, indicating that IL-33 functions independently or downstream of TSLP. Interestingly, loss of IL-33 expression ameliorated allergic symptoms even after sensitization, indicating that IL-33 may be an important target in both prevention and treatment of allergies (114).

Therapeutic strategies aimed at targeting IL-33 are being explored for their potential in treatment of allergies. Neutralizing IL-33 using subcutaneous injection of an anti-IL-33 mAb significantly improved $\mathrm{AD}$-like symptoms in a murine model of 2,4-dinitrochlorobenzene-induced AD, as demonstrated by reduced tissue eosinophil and mast cell counts and reduced serum IgE levels (115). Therapeutic antibodies targeting IL-33 (etokimab/ANBO20 and MEDI350) or the IL-33 receptor ST2 (RG 6149/AMG 282) are currently under development. Clinical trials are ongoing for the use of etokimab in $\mathrm{AD}$, peanut allergy, and allergic asthma. A phase IIa proof-of-concept study on the use of etokimab in peanut allergy showed that a single dose of $300 \mathrm{mg}$ etokimab improved tolerance to an oral challenge in 6 of 13 patients who exhibited moderate to severe symptoms at baseline (NCT02920021). It is difficult to conclusively interpret the induction of immune tolerance with this number of patients. A recent phase IIa proof-of-concept trial for the treatment of moderate to severe AD demonstrated that a single dose of etokimab led to decreased clinical severity (demonstrated by $50 \%$ reduction of the eczema area and severity index [EASI] score 57 days after treatment). This was associated with a decrease in circulating eosinophils and IL-33-mediated IFN- $\gamma$ release (NCT03533751) (116). Etokimab is currently also being investigated in phase II clinical trials for its effect on CRS with nasal polyps (NCT03614923) and severe eosinophilic asthma (NCT03469934). MEDI3506 is currently being tested in a phase I trial for chronic obstructive pulmonary disease (COPD) (NCT03096795). The anti-ST2 drug candidate RG 6149/AMG 282 has been tested in a phase I trial in CRS patients with nasal polyps, but no results have been published (NCT02170337). Moreover, recruitment for a phase II trial for treatment of COPD is ongoing (NCT03615040).

Given the potential functional redundancy of TSLP, IL-25, and IL-33 in the induction of Th2 responses, which is not caused by molecular or signaling pathway similarity, isolated neutralization of these molecules may fail to yield the desired clinical effect. In a murine model of helminth infection and chronic lung inflammation, neutralizing TSLP, IL-25, or IL-33 individually did not prevent the development of Th2-dependent inflammation and fibrosis (117). Only simultaneous blockade of all three mediators 
led to reductions in eosinophils, fibrosis, and ILC2s. Similar results were found in a model of house dust mite-induced allergic airway hypersensitivity (117). These data indicate that monotherapy targeting individual cytokines may not be sufficient in certain cases of progressive type 2 -driven disease, and combination therapy could be considered. While these preclinical studies targeting TSLP, IL-33, and IL-25 simultaneously showed a superior effect on the inhibition of Th2 responses, it should noted here that combination therapy with three new biologics in humans is currently not possible. The increased complexity associated with the use of combinations of novel biologics may lead to unexpected side effects and increased toxicity. One innovative approach that is being pursued is the design of novel highly potent bispecific anti-TSLP/IL-13 antibodies called Zweimabs (monovalent bispecific) and Doppelmabs (bivalent bispecific) that concurrently inhibit signaling by these two cytokines (118).

\section{Targeting IgE and IgE-expressing B cells}

Because of its key role in type I hypersensitivity reactions, IgE has always been a prime target for intervention in allergic disease. This has been approached from two different angles: (a) targeting soluble IgE and (b) targeting B cells that express surface IgE (119). Another less specific approach for targeting IgE production has been the depletion of all B cells using the anti-CD2O antibody rituximab (Figure 3).

Despite its critical role in allergies, surprisingly little is known regarding the regulation of $\operatorname{IgE}$ production in humans. This fact relates primarily to the extremely low frequency of IgE-switched memory B cells. It remains challenging to accurately detect and purify these cells from humans. A large body of research has convincingly demonstrated that IgE production is highly dependent on Th2 responses, in particular IL-4 and IL-13 signaling (120). The main question that still remains incompletely answered pertains to the location of IgE memory. Which cells form the basis of IgE memory? This is a critical issue, because these cells should be targeted to efficiently eliminate allergen-specific IgE. There are three possible major cell types that could form a reservoir for the IgE memory response: (a) IgE-switched memory B cells, (b) longliving plasma cells that primarily reside in the bone marrow (121), and (c) memory B cells that switched to any isotype within the IgH (immunoglobulin heavy chain) locus located between IgHD and IgHE (in humans these are IgG3, IgG1, IgA1, IgG2, and IgG4, and in mice, IgG3, IgG1, IgG2b, and IgG2a), because these cells can develop into IgE-switched B cells through a process called sequential class switch recombination $(122,123)$. Our ability to design the optimal strategy for targeting IgE memory responses will strongly improve if we can define which $\operatorname{IgH}$ isotype is the major contributor to IgE memory.

Currently, omalizumab is the only efficacious IgE-targeting antibody licensed for the treatment of allergic asthma and chronic spontaneous urticaria (124-130). Preliminary data indicate that patients suffering from systemic mastocytosis may also benefit from omalizumab treatment (131). Omalizumab binds soluble IgE, thereby preventing its binding to IgE receptors on effector cells (Figure 3). Interestingly, omalizumab treatment also leads to a reduction of FceRI on mast cells, basophils, and DCs (132). Omalizumab is currently being tested for a wide range of allergic conditions and other pathologies (133). An additional anti-IgE antibody, ligelizumab (QGE031), that binds the $C \varepsilon 3$ domain of IgE with higher affinity than omalizumab is currently in clinical testing (Figure 3). Ligelizumab was found to have a larger suppressive effect than omalizumab on circulating IgE, basophil FceRI expression, and skin prick test responses to allergens (134). A controlled trial in 37 mild allergic asthma patients demonstrated that ligelizumab has greater efficacy than omalizumab against inhaled and skin allergic responses (135). However, both antibodies neutralize serum IgE without affecting IgE production by plasma cells. While this type of approach neutralizes IgE-mediated type I hypersensitivity reactions, it has no impact on the IgE production, necessitating treatment at regular intervals of 2-4 weeks (125). Clinical studies are ongoing for urticaria (NCT03437278, NCT02649218).

An alternative strategy to interfere with IgE production involves the use of antibodies that bind to the membrane-bound form of IgE, thereby targeting B cells expressing an $\operatorname{IgE} \mathrm{B}$ cell receptor (BCR). Quilizumab (MEMP1972A/RG7449) is a humanized mAb that binds to the M1' segment of IgE (136). This segment is only present on membrane IgE and not on free, soluble IgE (137). Therefore, quilizumab targets $\mathrm{IgE}^{+}$memory $\mathrm{B}$ cells and plasmablasts, while long-lived IgE-switched plasma cells, which do not express surface IgE, are not targeted (Figure 3). Preclinical studies demonstrated that targeting the $\mathrm{M}^{\prime}$ domain of IgE efficiently reduced serum IgE without affecting other isotypes. Anti-M1' domain was an effective prophylactic and therapeutic therapy in murine models of allergic asthma and helminth infection (136). Despite yielding a significant reduction of total and allergen-specific IgE, quilizumab treatment did not impact asthma exacerbations, lung function, and symptom scores in a phase II trial that included 578 patients with inadequately controlled allergic asthma (138). Quilizumab reduced circulating IgE antibodies between $30 \%$ and $40 \%$, while omalizumab treatment resulted in an $89 \%$ to $98 \%$ reduction (129). This indicates that targeting membrane IgE is not sufficient to remove the allergen-specific IgE to a degree that confers clinical improvement. Therefore, other potential compartments of IgE memory appear to play a key role in the production of clinically relevant, allergen-specific IgE. These may include long-living plasma cells or subpopulations of memory B cells of other isotypes that can undergo a secondary switch to IgE upon reactivation.

MEDI4212, another IgE-targeting biologic, binds to soluble and membrane IgE. The main potential advantage of this approach is that it may achieve an immediate clinical benefit by directly targeting free $\operatorname{IgE}$, while limiting the generation of new IgE-switched B cells and plasma cells (ref. 139 and Figure 3). In a phase I study, atopic individuals were treated with a single dose of MEDI4212, omalizumab, or placebo. MEDI4212 treatment decreased serum IgE more rapidly than omalizumab treatment, but IgE recovery was also much more rapid than in the omalizumab-treated group (140). The short-lived suppression of serum IgE in MEDI4212-treated patients corresponded with a rapid decrease in serum levels of the therapeutic antibody, a feature that limits the potential for dosingschedule advantages over omalizumab.

A recent study showed that in a mouse model of peanut allergy and anaphylaxis, clinically relevant IgE titers were not sustained by long-living plasma cells but rather by allergen-specific memory 
B cells that replenish the IgE-switched plasma cell compartment (141). It remains to be determined whether the same applies to other models and how this finding translates to the human system. Notably, treating AD patients with the anti-CD2O antibody rituximab, which depletes all circulating B cells (but only a fraction of $B$ cells in various tissues), did not result in a reduction of allergenspecific IgE 4 to 8 weeks after treatment. This suggests that plasma cells can maintain IgE production for weeks to months without replenishment from circulating memory cells, or, alternatively, that tissue-resident memory B cells can replace circulating cells following depletion (142). Strategies that target these populations could be considered but may cause undesired side effects, because broadly targeting plasma cells or major memory B cell populations will impair protective humoral immunity against pathogens.

\section{Conclusion}

Allergies affect almost 1 billion people worldwide (143). A balance between immune tolerance and immune effector functions of innate and adaptive immune response has been shown to be decisive in allergy development and treatment. Various models have been used to study the mechanisms of immune tolerance, including AIT in patients, beekeepers, and cat owners who are chronically exposed to high doses of allergens. In addition to allergy vaccines, strategiestoinduceimmunetolerance, such as directed therapiesthat target specific mediators of allergic reactions, show great promise. Humanized antibodies that target essential cytokines, cytokine receptors, and soluble or membrane-bound IgE are promising approaches to the treatment of asthma, $\mathrm{AD}$, allergic rhinitis, and food allergy, some of which are in clinical use. These approaches can be categorized by their modulation of type 2 immunity: targeting the classical Th2 effector molecules by interfering with IL-4 and IL-13; interfering with eosinophil responses by targeting IL-5; interfering with Th2 and mast cell responses by targeting IL-9; fighting the itch response by targeting IL-31; and interfering with epithelium-immune cell interaction by targeting IL-25, IL-33, and TSLP, or by targeting soluble or cell surface-bound IgE. It should be noted here that downregulation of a general type 2 response may have certain consequences for immune responses in which Th2 cells, eosinophils, and type 2 effector cytokines such as IL-4, $\mathrm{IL}-5$, and IL-13 play a role. Parasitic infections and downregulation and control of extensive type 1 immune responses that are dominant in autoimmunity represent two main conditions that must be sorted out in multicenter studies. All of these effector molecules target upstream or downstream events in type 2 immune response, omitting only a fraction of patients who lack a predominant type 2 immune response. Patients with non-type 2 response, such as intrinsic type of AD, non-eosinophilic asthma, CRS without nasal polyps, neutrophilic asthma, and obesity-induced asthma, have not so far been efficiently targeted with biologics. While there are obvious similarities, there are also evident clinical, immunological, and pathological divergences between asthma, allergic rhinitis, nasal polyps, food allergy, and EoE. Current approaches targeting type 2 immunity seem to affect overlapping patient groups and produce similar final physiopathological outcomes. Extensive research in the area is needed, and given the rapid developments in such a short time, a brighter future is ahead for a variety of allergic diseases.

\section{Acknowledgments}

Funding is provided by the Center for Allergy Research and Education (CARE) of Switzerland (to CK) and the Swiss National Science Foundation (grant 320030-159870, 310030_179428).

Address correspondence to: Mübeccel Akdis, Swiss Institute of Allergy and Asthma Research (SIAF), University of Zurich, Oberestrasse 22, CH-7270 Davos Platz, Switzerland. Phone: 41.0.814100848; Email: akdism@siaf.uzh.ch.
1. Akdis M, et al. Interleukins (from IL-1 to IL-38), interferons, transforming growth factor $\beta$, and TNF- $\alpha$ : receptors, functions, and roles in diseases. J Allergy Clin Immunol. 2016;138(4):984-1010.

2. van Neerven RJ, Knol EF, Ejrnaes A, Würtzen PA. IgE-mediated allergen presentation and blocking antibodies: regulation of T-cell activation in allergy. Int Arch Allergy Immunol. 2006;141(2):119-129.

3. Mudde GC, Bheekha R, Bruijnzeel-Koomen CA. IgE-mediated antigen presentation. Allergy. 1995;50(3):193-199.

4. Galli SJ, Tsai M, Piliponsky AM. The development of allergic inflammation. Nature. 2008;454(7203):445-454.

5. Gerber BO, Pichler WJ. Cellular mechanisms of $\mathrm{T}$ cell mediated drug hypersensitivity. Curr Opin Immunol. 2004;16(6):732-737.

6. Esteban-Gorgojo I, Antolín-Amérigo D, Domínguez-Ortega J, Quirce S. Non-eosinophilic asthma: current perspectives. J Asthma Allergy. 2018;11:267-281.

7. Muraro A, et al. Precision medicine in allergic disease - food allergy, drug allergy, and anaphylaxis-PRACTALL document of the European Academy of Allergy and Clinical Immunology and the American Academy of Allergy, Asthma and Immunology. Allergy. 2017;72(7):1006-1021.

8. Muraro A, et al. Precision medicine in patients

with allergic diseases: airway diseases and atopic dermatitis-PRACTALL document of the European Academy of Allergy and Clinical Immunology and the American Academy of Allergy, Asthma \& Immunology. J Allergy Clin Immunol. 2016;137(5):1347-1358.

9. Bachert C, Akdis CA. Phenotypes and emerging endotypes of chronic rhinosinusitis. J Allergy Clin Immunol Pract. 2016;4(4):621-628.

10. Akdis CA, et al. Endotypes and phenotypes of chronic rhinosinusitis: a PRACTALL document of the European Academy of Allergy and Clinical Immunology and the American Academy of Allergy, Asthma \& Immunology. J Allergy Clin Immunol. 2013;131(6):1479-1490.

11. Agache I, Akdis C, Jutel M, Virchow JC. Untangling asthma phenotypes and endotypes. Allergy. 2012;67(7):835-846.

12. Lötvall J, et al. Asthma endotypes: a new approach to classification of disease entities within the asthma syndrome. J Allergy Clin Immunol. 2011;127(2):355-360.

13. van de Veen W, Wirz OF, Globinska A, Akdis M. Novel mechanisms in immune tolerance to allergens during natural allergen exposure and allergen-specific immunotherapy. Curr Opin Immunol. 2017;48:74-81.

14. Jutel M, et al. International Consensus on Allergen Immunotherapy II: mechanisms, standardization, and pharmacoeconomics. JAllergy Clin Immunol. 2016;137(2):358-368.

15. Novak N, et al. Early suppression of basophil activation during allergen-specific immunotherapy by histamine receptor 2. JAllergy Clin Immunol. 2012;130(5):1153-1158.e2.

16. Akdis M, et al. Immune responses in healthy and allergic individuals are characterized by a fine balance between allergen-specific $\mathrm{T}$ regulatory 1 and T helper 2 cells. JExp Med. 2004;199(11):1567-1575.

17. Jutel M, Van de Veen W, Agache I, Azkur KA, Akdis M, Akdis CA. Mechanisms of allergen-specific immunotherapy and novel ways for vaccine development. Allergol Int. 2013;62(4):425-433.

18. Meiler F, Zumkehr J, Klunker S, Rückert B, Akdis CA, Akdis M. In vivo switch to IL-10-secreting T regulatory cells in high dose allergen exposure. JExp Med. 2008;205(12):2887-2898.

19. van de Veen W. The role of regulatory B cells in allergen immunotherapy. Curr Opin Allergy Clin Immunol. 2017;17(6):447-452.

20. Boonpiyathad T, et al. High-dose bee venom 
exposure induces similar tolerogenic B-cell responses in allergic patients and healthy beekeepers. Allergy. 2017;72(3):407-415.

21. van de Veen W, Stanic B, Wirz OF, Jansen K, Globinska A, Akdis M. Role of regulatory B cells in immune tolerance to allergens and beyond. J Allergy Clin Immunol. 2016;138(3):654-665.

22. van de Veen W, et al. IgG4 production is confined to human IL-10-producing regulatory B cells that suppress antigen-specific immune responses. J Allergy Clin Immunol. 2013;131(4):1204-1212.

23. Ryan JF, et al. Successful immunotherapy induces previously unidentified allergen-specific CD4 ${ }^{+}$T-cell subsets. Proc Natl Acad Sci U S A. 2016;113(9):E1286-E1295.

24. Wilson DR, et al. Grass pollen immunotherapy inhibits seasonal increases in basophils and eosinophils in the nasal epithelium. Clin Exp Allergy. 2001;31(11):1705-1713.

25. Aalberse RC, Platts-Mills TA, Rispens T. The developmental history of IgE and IgG4 antibodies in relation to atopy, eosinophilic esophagitis, and the modified TH2 response. Curr Allergy Asthma Rep. 2016;16(6):45.

26. van de Veen W, Akdis M. Role of IgG4 in IgE-mediated allergic responses. J Allergy Clin Immunol. 2016;138(5):1434-1435.

27. Shamji MH, et al. Biomarkers for monitoring clinical efficacy of allergen immunotherapy for allergic rhinoconjunctivitis and allergic asthma: an EAACI Position Paper. Allergy. 2017;72(8):1156-1173.

28. Orengo JM, et al. Treating cat allergy with monoclonal IgG antibodies that bind allergen and prevent IgE engagement. Nat Commun. 2018;9(1):1421.

29. Larsen LF, et al. A comparative study on basophil activation test, histamine release assay, and passive sensitization histamine release assay in the diagnosis of peanut allergy. Allergy. 2018;73(1):137-144.

30. Boyman O, et al. EAACI IG Biologicals task force paper on the use of biologic agents in allergic disorders. Allergy. 2015;70(7):727-754.

31. Lim HF, Nair P. Airway inflammation and inflammatory biomarkers. Semin Respir Crit Care Med. 2018;39(1):56-63.

32. Mjösberg J, et al. The transcription factor GATA3 is essential for the function of human type 2 innate lymphoid cells. Immunity. 2012;37(4):649-659.

33. Hamilton JD, Ungar B, Guttman-Yassky E. Drug evaluation review: dupilumab in atopic dermatitis. Immunotherapy. 2015;7(10):1043-1058.

34. Simpson EL, et al. Two phase 3 trials of dupilumab versus placebo in atopic dermatitis. $N$ EnglJ Med. 2016;375(24):2335-2348.

35. Beck LA, et al. Dupilumab treatment in adults with moderate-to-severe atopic dermatitis. N Engl J Med. 2014;371(2):130-139.

36. Rabe KF, et al. Efficacy and safety of dupilumab in glucocorticoid-dependent severe asthma. N Engl JMed. 2018;378(26):2475-2485.

37. Castro M, et al. Dupilumab efficacy and safety in moderate-to-severe uncontrolled asthma. $N$ Engl JMed. 2018;378(26):2486-2496.

38. Leckie MJ, et al. Effects of an interleukin- 5 blocking monoclonal antibody on eosinophils, airway hyper-responsiveness, and the late asthmatic response. Lancet. 2000;356(9248):2144-2148.

39. Bachert C, et al. Effect of subcutaneous dupilumab on nasal polyp burden in patients with chronic sinusitis and nasal polyposis: a randomized clinical trial. JAMA. 2016;315(5):469-479.

40. Jonstam K, et al. Dupilumab reduces local type 2 pro-inflammatory biomarkers in chronic rhinosinusitis with nasal polyposis [published online ahead of print November 28, 2018]. Allergy. https://doi.org/10.1111/all.13685.

41. Kaye A, Gordon SC, Deverapalli SC, Her MJ, Rosmarin D. Dupilumab for the treatment of recalcitrant bullous pemphigoid. JAMA Dermatol. 2018;154(10):1225-1226.

42. Corren J, et al. A randomized, controlled, phase 2 study of AMG 317, an IL-4Ralpha antagonist, in patients with asthma. Am J Respir Crit Care Med. 2010;181(8):788-796.

43. Pelaia G, Vatrella A, Maselli R. The potential of biologics for the treatment of asthma. Nat Rev Drug Discov. 2012;11(12):958-972.

44. Wenzel S, Wilbraham D, Fuller R, Getz EB, Long phre M. Effect of an interleukin-4 variant on late phase asthmatic response to allergen challenge in asthmatic patients: results of two phase $2 \mathrm{a}$ studies. Lancet. 2007;370(9596):1422-1431.

45. Slager RE, et al. IL-4 receptor polymorphisms predict reduction in asthma exacerbations during response to an anti-IL- 4 receptor $\alpha$ antagonist. J Allergy Clin Immunol. 2012;130(2):516-522.e4.

46. Corren J, et al. Lebrikizumab treatment in adults with asthma. N Engl JMed.2011;365(12):1088-1098.

47. Korenblat P, et al. Efficacy and safety of lebrikizumab in adult patients with mild-to-moderate asthma not receiving inhaled corticosteroids. Respir Med. 2018;134:143-149.

48. Borish LC, et al. Interleukin-4 receptor in moderate atopic asthma. A phase I/II randomized, placebo-controlled trial. Am J Respir Crit Care Med. 1999;160(6):1816-1823.

49. Borish LC, et al. Efficacy of soluble IL-4 receptor for the treatment of adults with asthma. JAllergy Clin Immunol. 2001;107(6):963-970.

50. Nussbaum JC, et al. Type 2 innate lymphoid cells control eosinophil homeostasis. Nature. 2013;502(7470):245-248.

51. Warren HS, Kinnear BF, Phillips JH, Lanier LL. Production of IL- 5 by human NK cells and regulation of IL-5 secretion by IL-4, IL-10, and IL-12. J Immunol. 1995;154(10):5144-5152.

52. Desreumaux $P$, et al. Interleukin 5 messenger RNA expression by eosinophils in the intestinal mucosa of patients with coeliac disease. J Exp Med.1992;175(1):293-296.

53. Yanagibashi T, Satoh M, Nagai Y, Koike M, Takatsu K. Allergic diseases: from bench to clinic - contribution of the discovery of interleukin-5. Cytokine. 2017;98:59-70.

54. Robida PA, Puzzovio PG, Pahima H, Levi-Schaffer F, Bochner BS. Human eosinophils and mast cells: birds of a feather flock together. Immunol Rev. 2018;282(1):151-167.

55. Bagnasco D, Ferrando M, Varricchi G, Puggioni F, Passalacqua G, Canonica GW. Anti-interleukin 5 (IL-5) and IL-5Ra biological drugs: efficacy, safety, and future perspectives in severe eosinophilic asthma. Front Med (Lausanne). 2017;4:135.

56. Farne HA, Wilson A, Powell C, Bax L, Milan SJ.
Anti-IL5 therapies for asthma. Cochrane Database Syst Rev. 2017;9:CD010834.

57. Goldman M, Hirsch I, Zangrilli JG, Newbold P, $\mathrm{Xu}$ X. The association between blood eosinophil count and benralizumab efficacy for patients with severe, uncontrolled asthma: subanalyses of the Phase III SIROCCO and CALIMA studies. Curr Med Res Opin. 2017;33(9):1605-1613.

58. Bleecker ER, et al. Efficacy and safety of benralizumab for patients with severe asthma uncontrolled with high-dosage inhaled corticosteroids and long-acting $\beta 2$-agonists (SIROCCO): a randomised, multicentre, placebo-controlled phase 3 trial. Lancet. 2016;388(10056):2115-2127.

59. Chupp GL, et al. Efficacy of mepolizumab add-on therapy on health-related quality of life and markers of asthma control in severe eosinophilic asthma (MUSCA): a randomised, double-blind, placebo-controlled, parallel-group, multicentre, phase 3b trial. Lancet Respir Med. 2017;5(5):390-400.

60. Ortega HG, et al. Mepolizumab treatment in patients with severe eosinophilic asthma. $N$ Engl J Med. 2014;371(13):1198-1207.

61. Castro M, et al. Reslizumab for inadequately controlled asthma with elevated blood eosinophil counts: results from two multicentre, parallel, double-blind, randomised, placebo-controlled, phase 3 trials. Lancet Respir Med. 2015;3(5):355-366.

62. Murphy K, et al. Long-term safety and efficacy of reslizumab in patients with eosinophilic asthma. JAllergy Clin Immunol Pract. 2017;5(6):1572-1581.e3.

63. Ortega HG, et al. Severe eosinophilic asthma treated with mepolizumab stratified by baseline eosinophil thresholds: a secondary analysis of the DREAM and MENSA studies. Lancet Respir Med. 2016;4(7):549-556.

64. Bachert C, et al. Reduced need for surgery in severe nasal polyposis with mepolizumab: randomized trial. J Allergy Clin Immunol. 2017;140(4):1024-1031.e14.

65. Stein ML, et al. Anti-IL-5 (mepolizumab) therapy for eosinophilic esophagitis. J Allergy Clin Immunol. 2006;118(6):1312-1319.

66. Straumann A, et al. Anti-interleukin-5 antibody treatment (mepolizumab) in active eosinophilic oesophagitis: a randomised, placebo-controlled, double-blind trial. Gut. 2010;59(1):21-30

67. Assa'ad AH, et al. An antibody against IL-5 reduces numbers of esophageal intraepithelial eosinophils in children with eosinophilic esophagitis. Gastroenterology. 2011;141(5):1593-1604.

68. Hassani M, Koenderman L. Immunological and hematological effects of IL-5(R $\alpha)$-targeted therapy: an overview. Allergy. 2018;73(10):1979-1988.

69. Otani IM, Nadeau KC. Biologic therapies for immunoglobulin E-mediated food allergy and eosinophilic esophagitis. Immunol Allergy Clin North Am. 2017;37(2):369-396.

70. Schmitt E, et al. IL-9 production of naive CD $4^{+}$ $T$ cells depends on IL-2, is synergistically enhanced by a combination of TGF-beta and IL-4, and is inhibited by IFN- $\gamma$. J Immunol. 1994;153(9):3989-3996.

71. Gounni AS, et al. IL-9 expression by human eosinophils: regulation by IL- $1 \beta$ and TNF- $\alpha$. J Allergy Clin Immunol. 2000;106(3):460-466.

72. Stassen M, et al. Murine bone marrow-derived mast cells as potent producers of IL-9: costimulato- 
ry function of IL-10 and kit ligand in the presence of IL-1. J Immunol. 2000;164(11):5549-5555.

73. Abdelilah S, et al. Functional expression of IL-9 receptor by human neutrophils from asthmatic donors: role in IL-8 release. JImmunol. 2001;166(4):2768-2774.

74. Nagato T, et al. Expression of interleukin-9 in nasal natural killer/T-cell lymphoma cell lines and patients. Clin Cancer Res. 2005;11(23):8250-8257.

75. Veldhoen $M$, et al. Transforming growth factor- $\beta$ 'reprograms' the differentiation of $\mathrm{T}$ helper 2 cells and promotes an interleukin 9-producing subset. Nat Immunol. 2008;9(12):1341-1346.

76. Blom L, Poulsen BC, Jensen BM, Hansen A, Poulsen LK. IL-33 induces IL-9 production in human $\mathrm{CD} 4^{+} \mathrm{T}$ cells and basophils. PLoS One. 2011;6(7):e21695.

77. Sehra S, et al. TH9 cells are required for tissue mast cell accumulation during allergic inflammation. JAllergy Clin Immunol. 2015;136(2):433-440.e1.

78. Brough HA, et al. IL-9 is a key component of memory $\mathrm{TH}$ cell peanut-specific responses from children with peanut allergy. J Allergy Clin Immunol. 2014;134(6):1329-1338.e10.

79. Oh CK, Leigh R, McLaurin KK, Kim K, Hultquist $\mathrm{M}$, Molfino NA. A randomized, controlled trial to evaluate the effect of an anti-interleukin-9 monoclonal antibody in adults with uncontrolled asthma. Respir Res. 2013;14:93.

80. Shin JH, et al. Anti-interleukin-9 antibody increases the effect of allergen-specific immunotherapy in murine allergic rhinitis. Allergy Asthma Immunol Res. 2017;9(3):237-246.

81. Bağci IS, Ruzicka T. IL-31: a new key player in dermatology and beyond. J Allergy Clin Immunol. 2018;141(3):858-866.

82. Furue M, Yamamura K, Kido-Nakahara M, Nakahara T, Fukui Y. Emerging role of interleukin-31 and interleukin-31 receptor in pruritus in atopic dermatitis. Allergy. 2018;73(1):29-36.

83. Stott B, Lavender P, Lehmann S, Pennino D, Durham S, Schmidt-Weber CB. Human IL-31 is induced by IL- 4 and promotes TH2-driven inflammation. J Allergy Clin Immunol. 2013;132(2):446-454.e5.

84. Ruzicka T, et al. Anti-interleukin-31 receptor a antibody for atopic dermatitis. $N$ Engl J Med. 2017;376(9):826-835.

85. Kabashima K, et al. Nemolizumab in patients with moderate-to-severe atopic dermatitis: randomized, phase II, long-term extension study. J Allergy Clin Immunol. 2018;142(4):1121-1130.e7.

86. Hawro T, Saluja R, Weller K, Altrichter S, Metz M, Maurer M. Interleukin-31 does not induce immediate itch in atopic dermatitis patients and healthy controls after skin challenge. Allergy. 2014;69(1):113-117.

87. Divekar R, Kita H. Recent advances in epithelium-derived cytokines (IL-33, IL-25, and thymic stromal lymphopoietin) and allergic inflammation. Curr Opin Allergy Clin Immunol. 2015;15(1):98-103.

88. Ogasawara N, et al. Epithelial activators of type 2 inflammation: elevation of thymic stromal lymphopoietin, but not IL-25 or IL-33, in chronic rhinosinusitis with nasal polyps in Chicago, Illinois. Allergy. 2018;73(11):2251-2254.

89. Xu M, Dong C. IL-25 in allergic inflammation.
Immunol Rev. 2017;278(1):185-191.

90. von Moltke J, Ji M, Liang HE, Locksley RM. Tuft-cell-derived IL-25 regulates an intestinal ILC2-epithelial response circuit. Nature. 2016;529(7585):221-225.

91. Lee M, Kim DW, Shin HW. Targeting IL-25 as a novel therapy in chronic rhinosinusitis with nasal polyps. Curr Opin Allergy Clin Immunol. 2017;17(1):17-22.

92. Shin HW, et al. IL-25 as a novel therapeutic target in nasal polyps of patients with chronic rhinosinusitis. JAllergy Clin Immunol. 2015;135(6):1476-1485.e7.

93. Ballantyne SJ, et al. Blocking IL-25 prevents airway hyperresponsiveness in allergic asthma. JAllergy Clin Immunol. 2007;120(6):1324-1331.

94. Rusinova GG, Sharova EG, Libinzon RE. [The fate of homologous and heterologous DNA in animals]. Biokhimiia. 1969;34(3):464-471.

95. Soumelis V, et al. Human epithelial cells trigger dendritic cell mediated allergic inflammation by producing TSLP. Nat Immunol. 2002;3(7):673-680.

96. Sokol CL, Barton GM, Farr AG, Medzhitov R. A mechanism for the initiation of allergeninduced $\mathrm{T}$ helper type 2 responses. Nat Immunol. 2008;9(3):310-318.

97. Moon PD, Kim HM. Thymic stromal lymphopoietin is expressed and produced by caspase-1/ NF-kB pathway in mast cells. Cytokine. 2011;54(3):239-243.

98. Spadoni I, Iliev ID, Rossi G, Rescigno M. Dendritic cells produce TSLP that limits the differentiation of Th17 cells, fosters Treg development, and protects against colitis. Mucosal Immunol. 2012;5(2):184-193.

99. Ziegler SF, Roan F, Bell BD, Stoklasek TA, Kitajima M, Han H. The biology of thymic stromal lymphopoietin (TSLP). Adv Pharmacol. 2013;66:129-155.

100.Reche PA, et al. Human thymic stromal lymphopoietin preferentially stimulates myeloid cells. JImmunol. 2001;167(1):336-343.

101.Zhou B, et al. Thymic stromal lymphopoietin as a key initiator of allergic airway inflammation in mice. Nat Immunol. 2005;6(10):1047-1053.

102. Kabata H, Moro K, Koyasu S. The group 2 innate lymphoid cell (ILC2) regulatory network and its underlying mechanisms. Immunol Rev. 2018;286(1):37-52.

103. Ito T, et al. TSLP-activated dendritic cells induce an inflammatory $\mathrm{T}$ helper type 2 cell response through OX40 ligand. J Exp Med. 2005;202(9):1213-1223.

104.Ying S, et al. Thymic stromal lymphopoietin expression is increased in asthmatic airways and correlates with expression of Th2-attracting chemokines and disease severity. JImmunol. 2005;174(12):8183-8190.

105. He JQ, et al. A thymic stromal lymphopoietin gene variant is associated with asthma and airway hyperresponsiveness. J Allergy Clin Immunol. 2009;124(2):222-229.

106. Gauvreau GM, et al. Effects of an anti-TSLP antibody on allergen-induced asthmatic responses. N Engl J Med. 2014;370(22):2102-2110.

107. Simpson EL, et al. An anti-TSLP monoclonal antibody, in the treatment of moderate to severe atopic dermatitis: a randomized phase 2a clinical trial. J Am Acad Dermatol. 2019;80(4):1013-1021.
108. Corren J, et al. Tezepelumab in adults with uncontrolled asthma. $N$ Engl JMed 2017;377(10):936-946.

109. Schmitz J, et al. IL-33, an interleukin-1-like cytokine that signals via the IL-1 receptor-related protein ST2 and induces Thelper type 2-associated cytokines. Immunity. 2005;23(5):479-490.

110. Molofsky AB, Savage AK, Locksley RM. Interleukin-33 in tissue homeostasis, injury, and inflammation. Immunity. 2015;42(6):1005-1019.

111. Cayrol C, Girard JP. Interleukin-33 (IL-33): a nuclear cytokine from the IL-1 family. Immunol Rev. 2018;281(1):154-168.

112. Chu DK, et al. IL-33, but not thymic stromal lymphopoietin or IL-25, is central to mite and peanut allergic sensitization. J Allergy Clin Immunol. 2013;131(1):187-200.e1.

113. Wambre E, et al. A phenotypically and functionally distinct human $\mathrm{TH} 2$ cell subpopulation is associated with allergic disorders. Sci Transl Med. 2017;9(401):eaam9171.

114. Han H, Roan F, Johnston LK, Smith DE, Bryce PJ, Ziegler SF. IL-33 promotes gastrointestinal allergy in a TSLP-independent manner. Mucosal Immunol. 2018;11(2):394-403.

115. Peng G, et al. Anti-IL-33 antibody has a therapeutic effect in an atopic dermatitis murine model induced by 2, 4-dinitrochlorobenzene. Inflammation. 2018;41(1):154-163.

116. Chen Y, et al. First-in-class phase 2a study of anb020 (anti-il-33) in the treatment of moderate-to-severe atopic dermatitis. Oral abstract presented at: European Academy of Allergy and Clinical Immunology, Congress 2018. 2018 May 26-30. https://onlinelibrary.wiley.com/ doi/epdf/10.1111/all.13535 (abstract no. 0137). Accessed February 28, 2019.

117. Vannella KM, et al. Combinatorial targeting of TSLP, IL-25, and IL-33 in type 2 cytokine-driven inflammation and fibrosis. Sci Transl Med. 2016;8(337):337ra65.

118. Venkataramani S, et al. Design and characterization of Zweimab and Doppelmab, high affinity dual antagonistic anti-TSLP/IL13 bispecific antibodies. Biochem Biophys Res Commun 2018;504(1):19-24.

119. Hu J, Chen J, Ye L, Cai Z, Sun J, Ji K. Anti-IgE therapy for IgE-mediated allergic diseases: from neutralizing $\operatorname{IgE}$ antibodies to eliminating $\operatorname{IgE}+\mathrm{B}$ cells. Clin Transl Allergy. 2018;8:27.

120. He JS, Narayanan S, Subramaniam S, Ho WQ, Lafaille JJ, Curotto de Lafaille MA. Biology of IgE production: IgE cell differentiation and the memory of IgE responses. Curr Top Microbiol Immunol. 2015;388:1-19.

121. Luger EO, Wegmann M, Achatz G, Worm M, Renz $\mathrm{H}$, Radbruch A. Allergy for a lifetime? Allergol Int . 2010;59(1):1-8.

122. Looney TJ, et al. Human B-cell isotype switching origins of IgE. J Allergy Clin Immunol. 2016;137(2):579-586.e7.

123.Xiong H, Dolpady J, Wabl M, Curotto de Lafaille MA, Lafaille JJ. Sequential class switching is required for the generation of high affinity IgE antibodies. J Exp Med. 2012;209(2):353-364.

124. Maurer M, et al. Omalizumab for the treatment of chronic idiopathic or spontaneous urticaria. 
NEngl JMed. 2013;368(10):924-935.

125. Strunk RC, Bloomberg GR. Omalizumab for asthma. N Engl JMed. 2006;354(25):2689-2695.

126. Holgate ST, et al. Efficacy and safety of a recombinant anti-immunoglobulin $\mathrm{E}$ antibody (omalizumab) in severe allergic asthma. Clin Exp Allergy. 2004;34(4):632-638.

127. Milgrom $\mathrm{H}$, et al. Treatment of childhood asthma with anti-immunoglobulin $\mathrm{E}$ antibody (omalizumab). Pediatrics. 2001;108(2):E36.

128. Solèr M, et al. The anti-IgE antibody omalizumab reduces exacerbations and steroid requirement in allergic asthmatics. Eur Respir J. 2001;18(2):254-261.

129. Busse W, et al. Omalizumab, anti-IgE recombinant humanized monoclonal antibody, for the treatment of severe allergic asthma. J Allergy Clin Immunol. 2001;108(2):184-190.

130. Trischler J, et al. Omalizumab effectively protects against early and late allergic responses in asthma after 4 weeks. Allergy. 2017;72(12):1912-1915.

131. Broesby-Olsen S, et al. Omalizumab prevents anaphylaxis and improves symptoms in systemic mastocytosis: efficacy and safety observations.
Allergy. 2018;73(1):230-238.

132. Beck LA, Marcotte GV, MacGlashan D, Togias A, Saini S. Omalizumab-induced reductions in mas cell FceRI expression and function. J Allergy Clin Immunol. 2004;114(3):527-530.

133. Incorvaia C, Mauro M, Makri E, Leo G, Ridolo E. Two decades with omalizumab: what we still have to learn. Biologics. 2018;12:135-142.

134.Arm JP, et al. Pharmacokinetics, pharmacodynamics and safety of QGEO31 (ligelizumab), a novel high-affinity anti-IgE antibody, in atopic subjects. Clin Exp Allergy. 2014;44(11):1371-1385.

135. Gauvreau GM, et al. Efficacy and safety of multiple doses of QGE031 (ligelizumab) versus omalizumab and placebo in inhibiting allergen-induced early asthmatic responses. JAllergy Clin Immunol. 2016;138(4):1051-1059.

136. Brightbill HD, et al. Antibodies specific for a segment of human membrane IgE deplete IgE-producing B cells in humanized mice. J Clin Invest. 2010;120(6):2218-2229.

137. Zhang K, Saxon A, Max EE. Two unusual forms of human immunoglobulin $\mathrm{E}$ encoded by alternative RNA splicing of epsilon heavy chain mem- brane exons. J Exp Med. 1992;176(1):233-243.

138. Harris JM, et al. A randomized trial of the efficacy and safety of quilizumab in adults with inadequately controlled allergic asthma. Respir Res. 2016;17:29.

139. Nyborg AC, et al. Development of an antibody that neutralizes soluble IgE and eliminates IgE expressing B cells. Cell Mol Immunol. 2016;13(3):391-400.

140.Sheldon E, et al. Pharmacokinetics, pharmacodynamics, and aafety of MEDI4212, an anti-ige monoclonal antibody, in subjects with atopy: a phase I study. Adv Ther. 2016;33(2):225-251.

141. Jiménez-Saiz R, et al. Lifelong memory responses perpetuate humoral TH2 immunity and anaphylaxis in food allergy. J Allergy Clin Immunol. 2017;140(6):1604-1615.e5.

142.Simon D, Hösli S, Kostylina G, Yawalkar N, Simon HU. Anti-CD2O (rituximab) treatment improves atopic eczema. J Allergy Clin Immunol. 2008;121(1):122-128.

143. Pawankar R, Canonica GW, Holgate ST, Lockey RF, Blaiss M, eds. The World Allergy Organization (WAO) White Book on Allergy (Update 2013). Milwaukee, Wisconsin, USA: World Allergy Organization; 2013. 